\title{
Is the Stability of a Standard Stable Reference Stable Enough?
}

\author{
Umarevathi Gopalakrishnan ${ }^{1}$, Lodd Mahendra ${ }^{2}$ \\ The Journal of Contemporary Dental Practice (2020): 10.5005/jp-journals-10024-2795
}

The dogmatic approach of following the past principles has made many significant features of science go unnoticed and unquestioned. One such is the concept of immutability of the anterior contour of the sella turcica. For many decades, we have been using the anterior contour of sella turcica as a stable reference structure to study the growth of the craniofacial skeleton. ${ }^{1}$ This was based on the usage by Björk and Skieller. But on analyzing the various studies on the growth and disease of the pituitary gland and its influence on the size and morphology of sella turcica, it seems that the anterior contour of the sella turcica may not be a stable parameter of reference. This article is an attempt to throw light on the intricacies of the association between pituitary gland and sella turcica.

A twin study ${ }^{2}$ published on the morphology of the sella turcica gave insights that even within a monozygotic twin pair the morphology of sella varied, indicating the possibility of environmental influence on its morphology. There are literature reports of enlarged sella turcica in cases with pituitary tumors (adenomas, meningioma, prolactinoma, and craniopharyngioma), cystic lesion (Rathke's cleft cyst and mucocele), aneurysm, pituitary hyperplasia (primary hypothyroidism), acromegaly, gigantism, and Nelson syndrome ${ }^{3-9}$ whereas smaller sella turcica in primary hypopituitarism, growth hormone deficiency, Williams syndrome, and Cushing's syndrome due to adrenocortical adenoma. ${ }^{10-14}$ The fossa enjoying a unique relationship with the possibility of the pituitary gland dictating the remodeling of the fossa was suggested by Harry Israel as early as $1970 .^{15}$

A prior publication by the present authors ${ }^{16}$ hypothesized the pituitary gland to be the functional matrix of the sella turcica collecting literature evidences in favor of the same. There are literature evidences of the gland being formed before the formation of sella turcica. ${ }^{8,17-20}$ The article by Sheng and Westphal ${ }^{17}$ gave histological evidences showing the pituitary gland is formed before being saddled by the sella turcica and secreting hormones ${ }^{20}$ as early as the 8th week, indicating possibility of pituitary being the primary determinant of growth of sella. With regard to the size correlation, radiological images of sella turcica were used for diagnosing pituitary dimensions before the advent of MRI. ${ }^{21-25}$ Di Chiro and Nelson ${ }^{22}$ have shown a close correlation between pituitary gland and sella turcica when three dimensions of sella were measured. Not only the gland but the associated vascular plexus, ${ }^{15}$ connective tissue, ${ }^{26}$ and abnormal cerebrospinal fluid (CSF) influx ${ }^{27,28}$ were all reported to influence the size of sella turcica. A deficient sella diaphragm allows the influx of CSF, which in turn is reported to enlarge the sella. ${ }^{27}$ There are clear evidences of gradual pituitary enlargement during pregnancy ${ }^{29-31}$ of up to $45 \%$. Van Wyck and Grumbach $^{32}$ have noted that sella was responding to dimensional changes of the pituitary gland. While referring Van Wyck's study Harry Israel ${ }^{15}$ quoted, "They demonstrated contiguity of gland and fossa in a pathologic sequence where end organ disease, altered

\author{
${ }^{1,2}$ Department of Orthodontics, Sri Venkateswara Dental College and \\ Hospital, Chennai, Tamil Nadu, India
}

Corresponding Author: Umarevathi Gopalakrishnan, Department of Orthodontics, Sri Venkateswara Dental College and Hospital, Chennai, Tamil Nadu, India, Phone: +91 9841289794, e-mail: gopkr_uma@ yahoo.com

How to cite this article: Gopalakrishnan U, Mahendra L. Is the Stability of a Standard Stable Reference Stable Enough? J Contemp Dent Pract 2020;21(7):711-712.

Source of support: Nil

Conflict of interest: None

feedback, pituitary expansion and then corrective treatment in that order incorporated enlargement and demineralization of the pituitary fossa followed by a decrease in its size toward normal." Prenatal pathological conditions affecting morphology of the pituitary and sella turcica were studied by Inger $^{8}$ and he concluded that malformations in the pituitary gland might secondarily cause malformations in the sella turcica. We have clear evidences in the literature giving insights of the adaptability of the sella turcica based on the demands laid on it by the pituitary gland.

The orthodontic significance of this stems from the fact that the anterior contour of sella is considered as a stable reference structure for growth superimpositions. Studies by Björk ${ }^{1,33}$ and Riolo et al. ${ }^{34}$ suggested that the anterior contour of the sella turcica does not undergo any major structural alterations after the 6th or 7th year of life. The adaptable nature of sella has not been addressed in the orthodontic literature so far. Now that we know of a possibility that the sella turcica size and morphology may be influenced by the physiological and pathological alterations in the pituitary gland, the future use of the anterior contour of sella as a stable reference structure for superimpositions should be reconsidered.

\section{References}

1. Björk A, Skieller V. Normal and abnormal growth of the mandible. A synthesis of longitudinal cephalometric implant studies over a period of 25 years. Eur J Orthod 1983;5(1):1-46. DOI: 10.1093/ejo/5.1.1.

2. Brock-Jacobsen MT, Pallisgaard C, Kjaer I. The morphology of the Sella Turcica in monozygotic twins. Twin Research and Human Genetics 2009;12(6):598-604. DOI: 10.1375/twin.12.6.598.

3. Taveras JM, WoodEH.Diagnostic Neuroradiology.Baltimore:Williams \& Wilkins; 1976.

4. McLachlan MS, Wright AD, Doyle FH. Plain film and tomographic assessment of the pituitary fossa in 140 acromegalic patients. $\mathrm{Br}$ J Radiol 1970;43(510):360-369. DOI: 10.1259/0007-1285-43-510-360.

5. Friedland B, Meazzini MC. Incidental finding of an enlarged sella turcica on a lateral cephalogram. Am J Orthod Dentofacial Orthop 1996;110(5):508-512. DOI: 10.1016/s0889-5406(96)70057-4.

6. Pribram HW, Du Boulay GH, Newton TH, et al. Radiology of Skull and Brain. St Louis, Mo, USA: The C.V. Mosby Company; 1971. 
7. Swallow CE, Osborn AG. Imaging of sella and parasellar disease. Semin Ultrasound CT 1998;19(3):257-271. DOI: 10.1016/S0887-2171(98) 90011-7.

8. Kjær I. Sella turcica morphology and the pituitary gland-a new contribution to craniofacial diagnostics based on histology and neuroradiology. Eur J Orthod 2012;16:1-10.

9. Axelsson S, Storhaug K, Kjær I. Post-natal size and morphology of the sella turcica. longitudinal cephalometric standards for norwegians between 6 and 21 years of age. Eur J Orthod 2004;26(6):597-604. DOI: 10.1093/ejo/26.6.597.

10. Hubble D. Diagnosis of hypopituitarism in childhood. Arch Dis 1967;223(223):228-231. DOI: 10.1136/adc.42.223.228.

11. Lundberg PO, Gemzell C. Dysplasia of the sella turcica: clinical and laboratory investigations in three cases. ActaEndocrinol 1966;52(3):478-488. DOI: 10.1530/acta.0.0520478.

12. Fisher RL, Dichiro G. The small sella turcica. Am J Roentgenol 1964;91:996-1008.

13. Suba Anandhi K, Sanjeebkumar A, Indira Kumari MC. Abnormal small sella-a case report. J AnatSoc India 2009;58:13-15.

14. Steinbach HL, Noetzei M, Ozonoff MB. Small pituitary fossa in Cushing's syndrome due to adrenal neoplasm. N Engl J Med 1963;269(24):1286-1289. DOI: 10.1056/NEJM196312122692404.

15. Israel Harry. Continuing growth in sella turcica with age. Am J Roentgenol Radium Ther Nucl Med 1970;108(3):516-527. DOI: 10.2214/ ajr.108.3.516.

16. Gopalakrishnan U, Mahendra L, Rangarajan S, et al. Enigma behind pituitary. Case Rep Dent 2015. 954347. DOI: 10.1155/2015/954347.

17. Sheng $\mathrm{HZ}$, Westphal $\mathrm{H}$. Early steps in pituitary organogenesis. Trends Genet 1999;15(6):236-240. DOI: 10.1016/S0168-9525(99)01742-4.

18. Kjaer I, Fischer-Hansen B. The adenohypophysis and the cranial base in early human development. J Craniofac Genet Dev Biol 1995;15(3):157-161.

19. O'Rahilly R, Muller F. Minireview: summary of the initial development of the human nervous system. Teratol 1999;60(1):39-41.DOI: 10.1002/ (SICI)1096-9926(199907)60:1<39::AID-TERA11>3.0.CO;2-I.

20. Dubois PM, Begeot M, Dubois MP, et al. Immunocytological localization of $\mathrm{LH}, \mathrm{FSH}, \mathrm{TSH}$ and their subunits in the pituitary of normal and anencephalic human fetuses. Cell Tissue Res 1987;191:249-265.

21. Argyropoulou M, Perignon F, Brunelle $F$, et al. Height of normal pituitary gland as a function of age evaluated by magnetic resonance imaging in children. Pediatr Radiol 1991;21(4):247-249. DOI: 10.1007/ BF02018614.

22. Di Chiro G, Nelson KB. The volume of the sella turcica. Am J Roentgenol 1962;87:989-1008.

23. Hayakawa K, Konishi Y, Matsuda T, et al. Development and aging of brain midline structures: assessment with MR imaging. Radiol 1989;172(1):171-177. DOI: 10.1148/radiology.172.1.2740500.

24. Provenzale JM. Approaches to imaging of the sella: notes on the volume of the sella turcica. Am J Roentgenol 2006;186(4):931-932. DOI: 10.2214/AJR.05.1100.

25. Siverman FN. Roentgen standards size of the pituitary fossa from infancy through adolescence. Am J Roentgenol Radium Ther Nucl Med 1957;78:451-460.

26. Rasmussen AT. A quantitative study of the human hypophysis cerebri, or pituitary body. Endocrinol 1924;8(4):509-524. DOI: 10.1210/endo8-4-509.

27. Richard M, Horace N. Consequences of a deficient Sellar diaphragm. J Neurosurg 1970;32(5):565-573. DOI: 10.3171/jns.1970.32. 5.0565 .

28. Swartz JD, Russell KB, Basile BA, et al. High resolution computed tomography of the intrasellar contents: normal, near normal and abnormal. Radiographics 1983;3(2):228-247. DOI: 10.1148/ radiographics.3.2.228.

29. Gonzalez J, Elizondo G, Saldivar D, et al. Pituitary gland growth during normal pregnancy: an in vivo study using magnetic resonance imaging. Am J Med 1988;85(2):217-220. DOI: 10.1016/ s0002-9343(88)80346-2.

30. Hinshaw DB Jr, Hasso AN, Thompson JR, et al. High resolution computed tomography of the post partum pituitary gland. Neuroradiol 1984;26(4):299-301. DOI: 10.1007/BF00339774.

31. Goluboff LG, Ezrin C. Effect of pregnancy on the somatotroph and the prolactin cells of the human adenohypophysis. J Clin Endocrinol Metab 1969;29(12):1533-1543. DOI: 10.1210/jcem-29-12-1533.

32. Van Wyck JJ, Grumbach MM. Syndrome of precocious menstruation and galactorrhea in juvenile hypothyroidism. Pediat 1960;57(3): 416-435. DOI: 10.1016/S0022-3476(60)80250-8.

33. Björk A. Cranial base development. Am J Orthod 1955;41(3):198-225. DOI: 10.1016/0002-9416(55)90005-1.

34. Riolo LM, Moyers RE, McNamara JA, et al. An atlas of craniofacial growth. Ann Arbor: Center for Human Growth and Development, University of Michigan 1974. 